\title{
Pololos y medallas: la representación del deporte femenino en NO-DO (1943-1975) ${ }^{1}$
}

\author{
Fátima GIL GASCÓN \\ Universidad Internacional de La Rioja \\ fatima.gil@unir.net \\ José CABeza DeOgracias \\ Universidad Rey Juan Carlos \\ jose.cabeza@urjc.es
}

Recibido: 15 de febrero de 2012.

Aceptado: 21 de abril de 2012.

\begin{abstract}
Resumen
Esta investigación aborda la representación de la mujer en el deporte que proyectó el noticiario cinematográfico NO-DO en el período 1943-1975. La imagen que se ofrece de la mujer refuerza los estereotipos y el discurso dominante en dos diferentes espacios: los deportes considerados "femeninos", en los que se le permite participar, y los deportes "masculinos", en los que simplemente observa. En los dos ámbitos se repiten las mismas características: la mujer solo excepcionalmente recibe igualdad de trato con el hombre, se favorece una representación exclusivamente estética y se construyen piezas humorísticas en torno a su acercamiento y participación en la actividad deportiva.
\end{abstract}

Palabras clave: NO-DO; deporte; representación de la mujer; tauromaquia; Franquismo.

\section{Baggy pants and medals: female sport's representation in NO-DO (1943-1975)}

\begin{abstract}
This research analyses the women's image in sports that oficial newsreel NO-DO reflect and promote in the period 1943-1975. The women's image shown in this newsreeel reinforces all the stereotypes and the dominant discourse in two different key aspects: sports labeled as "for female" -women can take part in them and compete-, and sports labeled as "just for male" -women have an especific role here: be an spectator-. There are alike features in both spheres: there is just excepcionally equal informative treatment among genres, women's image mainly focuses on the aesthetic aspect and newsreel use them as a comic relief when they appear doing sports.
\end{abstract}

Key words: NO-DO; sports; women's image; bullfighting; Franquoism.

\section{Referencia normalizada}

Gil Gascón, F. y Cabeza Deogracias, J. (2012). Pololos y medallas: la representación del deporte femenino en NO-DO (1943-1975). Historia y Comunicación Social, Vol. 17, páginas 195-216.

Sumario: 1. Introducción. 2. La evolución del deporte femenino. 2.1. Lo que NO-DO mostró. 3. La mujer puede jugar: los deportes "femeninos". 4. La mujer no puede jugar: el fútbol. 5. El espectáculo taurino y la mujer: los límites deportivos. 6. Conclusión. 7. Bibliografía. 


\section{Introducción}

El estudio de la representación de la mujer en el deporte de la España franquista tiene interés porque no solo da idea de la imagen que las autoridades quieren difundir en esta esfera social, sino también porque trasciende a lo méramente físico y conforma todo un sistema de creencias destinado, específicamente, a enseñar cómo tienen que ser y comportarse las españolas. Hay que tener en cuenta que el deporte es la expresión de un sistema sociocultural y, por lo tanto, se constituye en espejo de los valores y rituales de las sociedades en los que se desarrolla (Guttmann, 1991). Da cuenta de qué principios son potenciados por un determinado grupo y cuáles son sus relaciones de género, el lugar que hombres y mujeres ocupan en el entramado social. Esta cuestión es especialmente evidente en una sociedad como la franquista, con una organización, Sección Femenina, encargada de velar por el mantenimiento de una visión muy tradicional de la mujer y con una conciencia muy clara de la funcionalidad y la finalidad de la "cultura física". El deporte no podía quedar al margen:

¿Cómo es la gimnasia femenina española? Es de tendencia neosueca con matizaciones típicamente españoles. Matices que van desde el conocimiento católico de la vida, con la supeditación de lo físico a lo moral, hasta la inclusión de temas populares españoles dentro de un marco típicamente femenino. Se busca una simultaneidad de la gimnasia con el juego y el deporte. Pero siempre teniendo en cuenta la particular psicología de la mujer y de la niña española. ${ }^{2}$

Para conocer el punto de vista que el franquismo quiso imponer en el imaginario colectivo se analiza un medio de comunicación que llegaba a amplios sectores de la sociedad: NO-DO, el noticiario oficial encargado de difundir los principios del régimen (Matud, 107). El deporte, como una forma de entender las relaciones de género ha sido abordado por varios estudios ${ }^{3}$. De igual manera otros trabajos han ahondado en el análisis del ejercicio físico femenino durante el franquismo aunque, la mayor parte de ellos, lo han hecho a través de los mecanismo impuestos por la Sección Femenina. ${ }^{4}$ A pesar de que, como se ha señalado, la organización falangista orquestaba la vida de las españolas, este no es el único medio de entender el tratamiento y la opinión que el Estado franquista desarrolló e impulsó sobre el deporte femenino.

El estudio de NO-DO presenta claras ventajas sobre el resto de los medios de comunicación de la misma época. Su carácter obligatorio convertía a la práctica totalidad de asistentes a los cines españoles en espectadores del noticiario cinematográfico oficial del franquismo. Su nivel de penetración era enorme. A ello hay que añadir las propias características de los mensajes audiovisuales que hacen aún más efectiva su repercusión en el receptor. La utilización de la emoción y los sentimientos tienen una incidencia más intensa en el espectador, más cuando se trata de cine y no de televisión: una sala oscura que centra la atención -incluso físicamente - en la pantalla, sin interferencias de las actividades cotidianas, con imágenes de gran tamaño, acompañamiento musical para subrayar la intensidad significativa de las imágenes (Paz, 2010). 
Otra lectura relevante, y en íntima relación con la anterior, es mostrar qué hechos considera un cámara dignos de ser conservados; incluso pueden descubrirse los valores que se asumen y los que se ignoran (Ferro, 1968: 581) en un periodo histórico determinado. Todos estos niveles de análisis presentan un enorme interés para este estudio y permiten visualizar los discursos dominantes de la época y su evolución en el tiempo, si la hubiera.

Por todo ello, la premisa de trabajo que se adopta en esta investigación es que las informaciones filmadas -el cine en general- referencian, más que cambian, la ideología latente en una determinada sociedad. Esa ideología es la que este estudio quiere recuperar a través, tanto el número de noticias que abordan esta cuestión, como del tratamiento que este medio otorga a las deportistas o al tipo de ejercicio que practican.

La metodología seguida en esta investigación ha consistido en primer lugar en una selección del material a partir de los sumarios de NO-DO. En segundo lugar, se analizó el material que aparecía relacionando deporte y mujer, ya fuera como informaciones dentro del noticiario o como reportajes que aparecen en Imágenes. Un total de 180 documentos audicovisuales. ${ }^{5}$ Básicamente, la mujer española aparece relacionada con el deporte en 3 categorías informativas diferentes dentro de NO-DO: las noticias relativas a las actividades deportivas patrocinadas por Sección Femenina, relativamente frecuentes en la década de los 40 y 50; los deportes universitarios, que poseen un cierto protagonismo a finales de los cincuenta y, sobre todo, en los sesenta; y campeonatos de diversa envergadura, con un carácter nacional en su mayoría, que se proyectan, con una cierta continuidad, a lo largo de toda la existencia del noticiario. Aquí se puede hablar de dos grandes bloques temáticos: por un lado, están los deportes "femeninos", es decir, aquellos que la mujer tiene posibilidad de practicarlos (gimnasia, esquí, natación...) y, por otro lado, se situaría el fútbol, un deporte de carácter más simbólico y masculino en el que el papel de la mujer se reduce, en la mayor parte de los casos y salvo extrañas excepciones, a un papel pasivo: nunca es participante, al menos no en serio, sino solo espectadora. El fútbol se convierte en un espacio social para la mujer, que sirve para definirla, lo mismo que sucede con los toros. Las noticias taurinas a veces aparecían dentro de la sección de deportes o en bloques informativos muy próximos. La mujer en este ámbito forma parte del espectáculo, pero con unas funciones y unos límites muy concretos. En este estudio también se busca demostrar que el rol que se le asigna a la mujer en el deporte se prolonga y extiende por muchos más espacios, como el mundo del toro.

Se realiza un estudio cuantitativo destinado a valorar la evolución de la representación de las práctivas deportivas de la mujer a lo largo de los años analizados (1943-1975) y las actividades - deportes- a los que la mujer aparece vinculada en la pantalla. Por otra parte, se lleva a cabo un análisis cualitativo que tiene en cuenta la locución que, en el caso de NO-DO, es muy importante porque generalmente da significado a la imagen, no es un mero complemento de ésta. También se analiza la imagen: dónde se sitúa la cámara, qué parte de la realidad escoge y con qué planos se presenta al espectador. Finalmente se analiza la realidad presentada: la relación de la mujer con otros protagonistas (otras mujeres, hombres y niños), los patrones de 
jerarquía, los estereotipos más frecuentes, las reiteraciones habituales y el tratamiento informativo que recibe la mujer.

Por último, se ha ampliado el análisis a las noticias relativas al deporte que aparecen en las revista de Sección Femenina Medina, publicada entre 1940 y 1945, y Teresa, editada desde 1954 hasta 1977 (ambas ubicadas en la Biblioteca Nacional) con el fin de ahondar en la visión que, sobre el ejercicio físico tenía la organización falangista, y poder situar los estereotipos más persistentes y aparentemente más cotidianos y compararlos con lo que aparecía reflejado en el NO-DO.

Se demostrará que NO-DO da cuenta de la mentalidad general que existía entonces con relación a este tema, pero también que fue un medio que sirvió para difundir el mensaje que el régimen tenía preparado para orientar la formación física de todas las españolas. Las actividades deportivas de la mujer, salvo excepciones, no eran consideradas profesionales y cualquier intento de cambio se observa desde un prisma entre excéptico y bromista.

\section{La evolución del deporte femenino}

El deporte fue reglamentado tras la victoria franquista como el resto de las disciplinas y organizaciones sociales. Desde 1941, la llamada "cultura física" estaba controlada por Falange 6 , tanto la que comenzó a considerarse obligatoria como aquélla que se realizaba de forma voluntaria a través de la afiliación a clubs. La actividad física, como en las potencias totalitarias del eje (Gori, 2003), fue entendida y utilizada, al menos durante los primeros años, como una potente herramienta para dominar y organizar a la población.

El desarrollo deportivo, como se encargó de transmitir el régimen, fue verdaderamente espectacular durante estos primeros años, especialmente el femenino. En 1939, la Sección Femenina celebró los primeros Campeonatos Nacionales en los que participaron 41 equipos formados por 1.200 deportistas. Casi 40 años después, en 1975, los equipos eran casi 10.000 y las muchachas que los componían más de 110.000 (Loring, 1983: 73). El acceso de las españolas a la práctica de este tipo de actividad fue progresiva y claramente beneficiada por la importancia que la Sección Femenina otorgó a la Educación física de la mujer incluso antes del final de la guerra. El anhelo de esta organización era imponer "un ejercicio físico y deportivo bien dirigido, que consiga no sólo el fortalecimiento y desarrollo corporal, sino el enriquecimiento de la persona a través de la aplicación de métodos pedagógicos adecuados" (Suárez, 1993: 110).

Así, el organismo regidor de la vida de las españolas consideraba que el deporte formaba tanto el cuerpo como el alma. Pero esta actividad tenía, además, 3 funciones principales: era un importante elemento propagandístico, un buen modo de ejercer cierta disciplina sobre las más jóvenes y una extraordinaria manera de controlar y mejorar las capacidades reproductoras de las españolas.

La primera de estas funciones se ejerció a través de la publicidad promovida, principalmente, por la propia organización falangista. Las deportistas que mostraban 
las revistas y el resto de los medios de comunicación eran fuertes, sanas y limpias, tal y como reza el pie de página de una foto publicada en el Anuario de Sección Femenina de 1941.7 También eran jóvenes y bien parecidas. Estas muchachas, junto con las que formaban los grupos de coros y danzas, que competían tanto en territorio español como extranjero, constituían una buena prueba de las cualidades que el franquismo pretendía potenciar en la mujer española (Amador, 2003). Tanto las competiciones como las exhibiciones de bailes regionales contribuían, además, a acrecentar el sentimiento patriótico de sus participantes. No en vano las deportistas y bailarinas estaban representando a su región o a su país en celebraciones donde la parafernalia que exaltaba "lo nacional" estaba claramente subrayada.

Pero el deporte también se utilizó, como se ha señalado, como medio para adoctrinar a las futuras españolas a través de las instrucciones que las chicas recibían en los centros educativos. No hay que olvidar que era una asignatura obligatoria desde la enseñanza primaria hasta la universidad (Rabazas, 2000). A pesar de su apariencia aséptica, esta disciplina no dejaba de situar a la alumna en un engranaje ideológico concreto. Según aclaraba Pilar Primo de Rivera, fundadora de Sección Femenina en 1939, año en el que se celebró el primer Campeonato Nacional de Deportes del SEU, quinto organizado por la Sección Femenina, el deporte femenino servía para:

Alcanzar la perfección del cuerpo, necesaria para el equilibrio de la persona humana; salud del alma, que necesitaba a su vez de ese equilibrio como parte de la formación religiosa, espíritu de competitividad que enseña a las mujeres a participar en todas las tareas (Suárez, 1993: 115).

El deporte adquiría de esta manera un trasfondo que excedía a la salud y a la mera diversión. Se alejaba de ser un fin en sí mismo para transformarse en un medio, una manera de inculcar a las mujeres la idea de esfuerzo y, sobre todo, la de sacrificio. Los contenidos de esta educación física se basaban en el método sueco: tablas uniformes, formaciones, desplieges, alineaciones y movimientos analíticos que posteriormente se irán adaptando a los nuevo tiempos e introduciendo movimientos ondulatorios, oscilaciones y vaivenes (Zagalaz, 1998: 208).

El tiempo y los cambios también llegarán en la forma de vestir. La mujer siempre debía mantener un cierto pudor para realizar ejercicios físicos por lo que, a principios de los 40, se estableció la necesidad de imponer un uniforme que permitiera a las deportistas libertad de movimiento sin perder el decoro. De esta manera se impusieron los pololos, unas faldas pantalones anchas que se ajustaban a las piernas por debajo de la rodilla. A medida que los tiempos cambiaban se observó la necesidad de modificar este uniforme, tal y como se comprueba en la entrevista que aparece en la revista Teresa a Alicia Lage, regidora central de Educación Física y Deportes de la Sección Femenina en 1969. La periodista y la falangista recogen la evolución de la vestimenta:

Le cuento a Alicia que hice gimnasia en el colegio con calcetines negros, cuello duro y uniforme. Y los bombachos debajo. Luego nos quitamos alguna cosa. Pero nunca tuvimos ducha y nos íbamos a casa sudorosas y hechas un asco. Muchas de 
nosotras le teníamos tirria a la gimnasia por eso. Prácticamente todo eso ha desaparecido (responde la falangista). Cada vez se hace gimnasia más en condiciones en todas partes. Con pantaloncitos cortos y lo que preciso. ${ }^{8}$

Pero la verdadera función función del desarrollo de la Educación física, al menos durante la posguerra, era, sin duda, el mejoramiento morfológico y funcional de la mujer, relacionado intrínsecamente con la maternidad. Durante el siglo XX se produce un cambio sustancial en la relación femenina con el deporte. Rechazado durante buena parte de la Historia, ${ }^{9}$ el nuevo siglo introdujo la idea, promovida en parte por las teórias eugenésicas en la Alemania nazi y en la Italia fascista (Morgan, 2006), de que determinados ejercicios eran cláramente beneficiosos para el organismo de las mujeres. Esto ayudaban a las jovencitas a mantenerse sanas y fuertes además de enseñarles disciplina y orden. Esta cuestión fue especialmente relevante en la postguerra, momento de una elevada mortandad infantil:

La mujer, por cuanto tiene encomendada una formación educadora inicial en la vida del niño, por madre, necesita, para desempeñarla, de una preparación justa. La educación física es, en este sentido, una de las enseñanzas que está obligada a recibir como mujer de un Estado fuerte y sano, el cual quiere recibir de sus súbditos esa fortaleza y esa salud que constituye su propio ser. La higiene, la gimnasia y el deporte hacen de cada una de nosotras esa mujer sana y limpia moralmente que el Estado quiere para madre de sus hombres del porvenir. ${ }^{\mathrm{X}}$

El deporte, siempre que no fuera excesivamente duro, se consideraba una excelente manera de moldear y preparar el cuerpo de las jóvenes para el fin al que, en último término, estaban destinadas: la maternidad. Una buena forma física facilitaba una mejor concepción. Teniendo en cuenta esta cuestión, los deportes considerados adecuados para la mujer por la Sección Femenina eran el voleibol, baloncesto, balonmano, hockey, natación, esquí y montañismo. Otros como el ciclismo o algunas pruebas de atletismo estaban prohibidos por considerarse poco femeninos (Zagalaz, 1998: 208) ${ }^{11} \mathrm{y}$, por tanto, poco recomendables para su delicado cuerpo.

\subsection{Lo que NO-DO mostró.}

En general, estos deportes, incluyendo la gimnasia, eran los que prevalecían en cantidad y dedicación en los noticiarios cinematográficos. En el período 1943-1975, el deporte femenino aparece reflejado en alguna noticia en 180 ocasiones. Por años, los 60 son los que ofrecen el mayor número de ediciones en las que aparecen mujer y deporte, ${ }^{12}$ seguidos de los 50, los 70 y, en último lugar, los 40 (Gráfico I). 
Gráfico I. Mujer y deporte. Noticias por décadas.

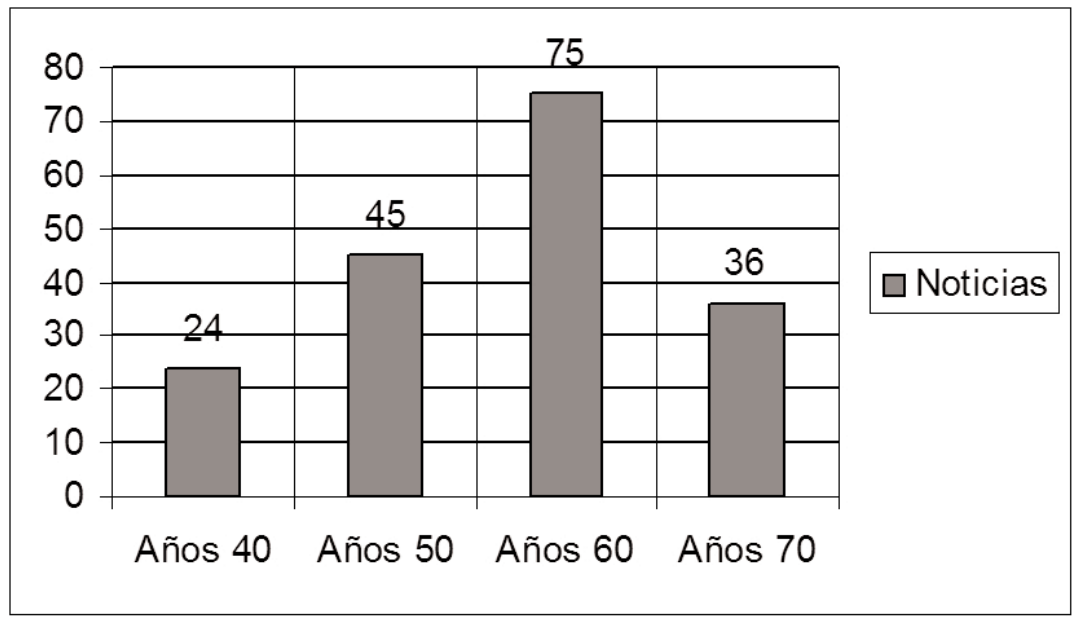

Fuente: Elaboración propia

Por deportes, las ediciones sobre pruebas de natación son las más numerosas (Gráfico II). Suelen referirse a eventos, Campeonatos de España, campeonatos y torneos locales (Campeonato de Castilla, de Palma de Mallorca), travesías -como la tradicional travesía de la Laguna de Peñalara, la travesía a nado del puerto de Barcelona, del Lago de Bañolas o de la bahía de Santander-, y ballet acuático y salto. Los campeonatos internacionales son escasos en esta modalidad. Con mucho menos de la mitad de noticias, le siguen el esquí y la gimnasia.

Gráfico II. Mujer y deporte. Noticias por especialidad.

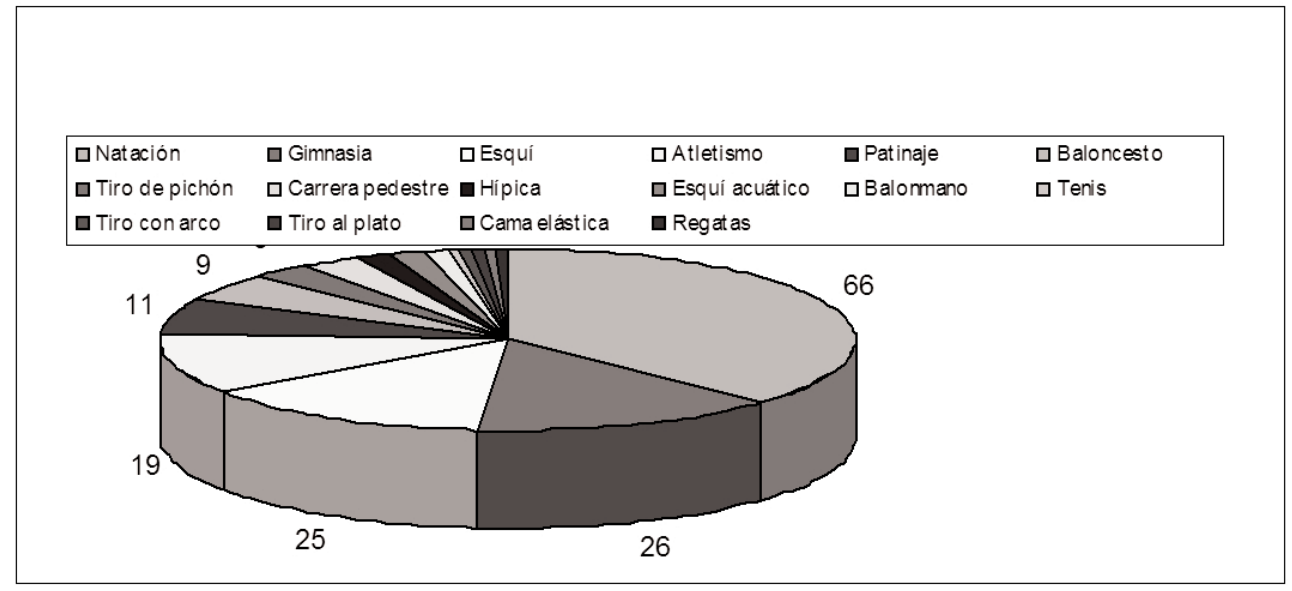

Fuente: Elaboración propia 
Por lo general, todas estas noticias no están dedicadas exclusivamente a la mujer. Normalmente, la información comienza por las pruebas masculinas, a las que se concede más importancia, y termina con las femeninas. Sólo en las competiciones con participación exclusiva de mujeres este orden visual no se cumple-actuación del ballet acuático de Madrid, por ejemplo-; o cuando se ha producido una incidencia llamativa, desde el punto de vista informativo -se bate un récord-, que sitúa a esta categoría en primer lugar.

\section{La mujer puede jugar: Los deportes "femeninos"}

En los deportes considerados tradicionalmente femeninos, es decir, aquellos que el régimen franquista concebía como adecuados para ellas, la mujer aparece en las informaciones de NO-DO como un elemento activo que participa en competiciones y otros encuentros deportivos, aunque con ciertos matices. A pesar de su progresiva incorporación a este mundo, la deportista no es representada de igual manera que sus compañeros. El ejercicio físico se ha relacionado históricamente con lo masculino. Es en los deportes donde se observa, incluso en la actualidad, la mayor separación entre ambos géneros (Díez, 1996). Esta diferenciación, completamente evidente en NO-DO, está, además, acompañada de una cierta condescendencia.

Este tratamiento puede observarse en la natación, disciplina que ocupa casi la mitad de las informaciones. Las noticias que emite NO-DO no suelen comparar las marcas masculinas y femeninas. El espectador percibe a los nadadores de ambos géneros como elementos cláramente diferenciados. Sin embargo, cuando aparecen juntos, siempre se utiliza para demostrar la inferioridad de la mujer: en la travesía al Puerto de Barcelona ${ }^{13}$ en 1958, por ejemplo, la ganadora, Carmen Santamaría, realizó una buena marca, pero la locución deja patente que, en la categoría masculina, se logró mejor tiempo. Otras veces se enfatiza la diferencia en el número de participantes: "10 nadadoras y 126 nadadores". ${ }^{14}$ Lo importante es marcar la distancia. Así, se establece una jerarquía de género que evidencia la inferioridad, al menos física, de las mujeres.

En consonancia con las pautas del periodismo deportivo más clásico, el deporte femenino también tiene sus nombres propios, sus referentes: Avelina La Casa, Marta González o Aurora Chamorro, entre otras muchas. Sin embargo, no son representaciones generales de todo el colectivo, sino que se entiende que se trata de una minoría, una elite profesional muy concreta. ¿Cuántas mujeres sabían nadar, por ejemplo, en los años 50? Y de éstas, ¿cuántas practicaban habitualmente la natación? Este dato enlaza con el hecho de que sean la Sección Femenina y el mundo universitario los ámbitos restringidos en los que se enmarcan este tipo de noticias. ${ }^{15}$

Precisamente en el tratamiento individualizado otorgado por el locutor a los deportistas, se observa un factor continuo de desigualdad. A ellos se les menciona con naturalidad por su nombre y apellido: son Felipe Fernández o Julián Falcón. A ellas se les añade un tratamiento de cortesía -la señorita- y les asignan diminutivos de forma habitual: la señorita Isabelita Castañé, la señorita Chelo Romo o Rosita 
Laguna. A través del lenguaje se pone de manifiesto la superioridad masculina sobre la inferioridad femenina. La trivialización de los comentarios añade, al desprecio visual, un desprecio verbal a estas informaciones deportivas referidas a la mujer.

En general, los primeros planos en bañador son escasos: la cámara filma a las nadadoras dentro del agua o fuera, cuando llevan chándal o albornoz (Suárez, 1993: 125), pero no puede decirse que exista un especial pudor por evitar este tipo de tomas, especialmente a partir de los 60. Lo que ocurre es que lo noticioso está en la competición, por tanto dentro de la piscina, o en la entrega de trofeos, cuando las nadadoras ya se han cambiado.

El segundo deporte con presencia femenina más visto es la gimnasia, que prácticamente monopoliza la Sección Femenina en informaciones referidas a exhibiciones, festivales, campeonatos nacionales o cursos de instructoras. En este deporte existe el anonimato. No son jóvenes concretas quienes ejecutan los ejercicios. Es la mujer española la que lleva a cabo la exhibición en un gesto de amor por su patria. Las pantallas presentan miles de afiliadas y cientos de equipos que "hacen gala de su armoniosa cadencia", bajo la dirección de la organización falangista. La gimnasia, como se ha visto, forma parte de sus preceptos: "el deporte hace lograr el difícil equilibrio entre el alma y el cuerpo".

En los 60, las noticias sobre gimnasia adquieren contenidos más variados y, sobre todo, un carácter más profesional: mujeres con nombres propios compiten con éxito en campeonatos nacionales e internacionales. No obstante, los festivales de Gimnasia -a veces de gimnasia y folclore- a cargo de la Sección Femenina se exhiben en pantalla hasta 1974. Interesaba mantener vivas estas exhibiciones que demostraban "el espíritu leal de colaboración entre todos sus elementos", 16 al menos, ése era el mensaje que la propaganda oficial pretendía difundir.

Con las mismas connotaciones se proyecta en las pantallas de toda España la práctica del esquí. Es también la Sección Femenina la que promociona este deporte: "La Sección Femenina cuida la educación deportiva de la mujer con gran interés".17 En este caso, el esquí se relaciona con educación física, humanismo y deporte. Muchas de estas noticias no tienen nada que ver con una práctica deportiva seria: las imágenes presentan a jóvenes que hacen muñecos de nieve, a los que ponen atuendos humorísticos, como caretas o narizotas de broma; y pruebas de obstáculos donde hay que salvar copas o platos con merengue. Si en alguna ocasión se habla de esquí en serio, la cámara presenta a hombres. Cuando el tono de la locución es distendido y se pretende provocar una sonrisa en el espectador, entonces aparecen las mujeres: "El más difícil todavía no podía faltar: el salto de noche". ${ }^{18}$ En pantalla una mujer luce un elegante camisón. En este caso, la importancia concedida a la vestimenta es mayor: así, la "elegancia femenina" se convierte en un requisito fundamental en las cumbres. ${ }^{19}$ En los 60 y 70, los campeonatos de España dan un aire más profesional a las pruebas. También las imágenes ganan calidad y vistosidad, gracias a la mejora técnica experimentada en esos años por NO-DO.

Durante los 40 y 50, los partidos de baloncesto femenino suelen celebrarse con motivo de alguna fiesta especial. Esto da una idea de las características del encuentro: las jugadoras no son profesionales y visten, muy pudorosamente, falda 
pantalón. Lo importante de sus pases es "la pericia y el completo adiestramiento", y suelen terminar el encuentro posando ante la cámara con el brazo en alto. Como en otros deportes -gimnasia o esquí-, la práctica del baloncesto femenino se vincula a la Sección Femenina-SEU, con las connotaciones políticas que ello implica. ${ }^{20}$ En realidad, en este tipo de pruebas importan las inauguraciones y los finales triunfales cargados de entusiasmo.

Llega a Barcelona la escuadra portadora del mensaje de Franco a los participantes de los $4^{\mathrm{a}}$ Juegos Universitarios nacionales. El jefe nacional del SEU da lectura a las cuartillas autógrafas del Generalísimo (...... ${ }^{21}$

En el atletismo, la mujer presenta un patrón bien distinto al que vemos en la gimnasia o en el esquí. Los aspectos que varían son: el cronológico, el ámbito de referencia y su representación. Durante los 40 y los 50 hay muy pocas informaciones sobre este deporte en el archivo de NO-DO. Sin embargo, aproximadamente a partir de 1963, se empiezan a estrenar noticias sobre atletismo femenino de forma periódica a través de la organización y cobertura de los campeonatos de España y de los Juegos Universitarios. La Sección Femenina no posee protagonismo en este tipo de pruebas y, tanto en las tomas como en los comentarios, las atletas españolas se presentan como preparadas físicamente y con espíritu competitivo. Se valora su esfuerzo y se ensalzan sus triunfos. En ocasiones se da la información alternando los resultados de los atletas masculinos y femeninos, pero rara vez se comparan las marcas conseguidas. ${ }^{22}$

El patinaje artístico es otro deporte en el que el noticiario franquista hace especial mención a la mujer. Normalmente se trata de festivales o exhibiciones, aunque también se filman campeonatos. La cámara se detiene en la belleza plástica del movimiento y la locución en el gesto femenino. Mientras una patinadora se abrocha el calzado, el locutor comenta: "Esta suiza tiene mucha cuerda (pausa) para sus botas"; o mientras una participante se coloca el moño, el locutor añade: "Esta francesita prefiere atender a su tocado". ${ }^{23}$ No se las considera como profesionales, sino algo así como muñecas que patinan. Eso sí, se insiste en la presencia de representantes de otros países, porque las pruebas parecen adquirir mayor importancia, aunque la cámara siempre concede el protagonismo a las patinadoras españolas -lo mismo puede decirse en otros deportes-, incluso aunque éstas queden en los últimos puestos.

En este deporte hay que esperar a los 70 para encontrar informaciones con algo más de rigor periodístico. Los comentarios irónicos son sustituidos por otros que, aunque no muy especializados, sí son, al menos, algo más serios: "Aquí la vemos mostrando su buena escuela ante el público". Se ofrecen vistas generales de la pista, imágenes de las diferentes pruebas individuales y por parejas, entrega de medallas y panorámicas del público.

En el resto de los deportes, la presencia femenina es mínima y el tratamiento audiovisual la reduce aún más. Los deportes femeninos se muestran como meros entretenimientos de esforzadas señoritas, muy alejados de la virilidad y el esfuerzo 
real de los masculinos. Por ejemplo, en la carrera pedestre se concede más importancia al circuito que a la participación o el resultado. El empeño se pone en demostrar que la prueba ha sido un éxito. Lo mismo sucede en hípica, donde, por ejemplo, la sensación que queda después de ver estas ediciones es que el caballo, y no la amazona, es el responsable del triunfo. A veces el protagonismo de una deportista se hace derivar de su condición de "esposa de". A la inversa no se constata este hecho.

\section{La mujer no puede jugar: el fútbol}

Junto a los deportes considerados tradicionalmente femeninos, NO-DO informa también de otro tipo de ejercicio muy valorado socialmente, pero alejado de la esfera femenina. En él la mujer participa de forma pasiva: formando parte del público. El fútbol es una disciplina considerada específicamente masculina. Es el paradigma de la fuerza, la potencia y la épica. Un mundo muy alejado de las mujeres, especialmente durante el franquismo. El régimen utilizó el fútbol, y también el mundo taurino, como un reclamo para la sociedad, una manera de crear una cultura de unidad nacional, orgullo patrio y grandeza de España (Hurelaga, 2009).

El fútbol no es un deporte adecuado para las mujeres por dos razones. La primera es la violencia de sus movimientos que, según la Sección Femenina, no se adecúa al organismo femenino:

(...) Vígaros son, que no mujeres, desprovistas de todas cualidades femeninas, aptas para cargadores de muelles o cosa parecida. Tristes ejemplos del fruto que puede dar una equivocada educación física... Estregarse en cuerpo y vida a deportes no adecuados puede terminar en convertir a la mujer en una máquina de dar patadas -como estas dos futbolistas una alemana y otra holandesa- o como esta monstruosa lanzadora de pesos rusa.

La dulzura, la gracia, la delicadeza, la armonía... características todas ellas que deben ser nuestras, que nunca debemos perder si conservamos nuestra categoría humana. Ellas las han perdido. Y no hay nada más triste y que más rebaja a una mujer que dejar de serlo o parecerlo". ${ }^{24}$

La segunda responde a una idea muy extendida: el fútbol es un deporte eminentemente masculino (González, 2005). Por ello, la ausencia de la mujer en el deporte de masas más importante durante el franquismo es casi absoluta. Al menos practicándolo. Las escasas veces que aparece una mujer en la pantalla corriendo detrás de un balón, se muestran otros aspectos que nada tienen que ver con lo meramente deportivo. Resulta muy significativo, porque reflejan cómo los hombres ven el fútbol femenino: una bufonada realizada, eso sí, por guapas jovencitas. Es, sin duda, el deporte en el que se aprecia mejor la mirada masculina tras el objetivo de la cámara de filmación.

Por encima de otras consideraciones periodísticas, lo que interesa en este caso es el cuerpo de la mujer. La cámara muestra especial predilección por enfocar determi- 
nadas partes de su anatomía; se recrea en las dificultades que origina un pantalón un poco ceñido y en las preocupaciones estéticas de las jugadoras durante el encuentro. El resto carece de mérito, porque, como dice la voz en off, "juegan al fútbol hasta los ciegos". ${ }^{25}$ Se considera que estas informaciones son menos emocionantes que la retransmisión de un encuentro de fútbol masculino, por lo que el gancho del evento se hace recaer - una vez más- en la tradicional y estereotipada mirada al cuerpo de la mujer.

Los encuentros de fútbol que filma NO-DO, y en los que participan mujeres, poseen casi siempre un carácter excepcional. Los partidos entre folclóricas y finolis, celebrados anualmente con fines benéficos en el campo del Rayo Vallecano, constituyen un ejemplo. Interesa en estos eventos divertir al público, que, ya se sabe, no acude al estadio para presenciar fútbol profesional, sino más bien para reír porque el árbitro suele intervenir con el pie; porque no se sabe si al final se han jugado dos o tres tiempos; y porque, en más de una ocasión, al masajista ha habido que sacarlo por la fuerza, ya que, en cada percance, aprovechaba la ocasión para aproximarse "sospechosamente" a las jugadoras. NO-DO muestra el fútbol como un deporte ajeno a las mujeres. Ellas no se sienten identificadas ni con el juego ni con el espectáculo que se desarrolla. Tampoco parecen, a juzgar por los testimonios de la época, sentirse demasiado interesadas en él. ${ }^{26}$ No ocurre lo mismo con los toros, ahí la mujer está presente, pero su representación en ese mundo tiene mucho que ver con los límites en los que se desenvuelve en el deporte.

\section{El espectáculo taurino y la mujer: los límites deportivos}

El espectáculo taurino es fundamental y tradicionalmente masculino, y las imágenes que aparecen en el noticiario franquista en este sentido no significan ninguna excepción. La presencia del toro impone un tono especial en la fiesta, impulsa la presencia de unos valores concretos sobre otros: bravura, valor, dominio o redaños, cualidades con las que normalmente se identifica más al hombre que a la mujer. El ruedo es pues un territorio masculino, pero esto no quiere decir que las mujeres queden excluidas del espectáculo, todo lo contrario, la mujer goza de un trato especial, pero su rol es completamente diferente. Ellas deben aparecer sentadas en el tendido, recibir el brindis de cada corrida y dar con su presencia sentido a la exhibición de valentía y de riesgo que los diestros llevan a cabo. La madre, la esposa, la hermana rezan, apoyan, comprenden y aman al torero, y por ello, reciben una consideración especial. Ése es el espacio más lógico de la mujer en el mundo taurino: alentar y acompañar al que desafía a la muerte en cada corrida. Además, un torero que se precie ha de estar rodeado de mujeres, a ser posible, guapas y distinguidas. Son una especie de trofeo que la sociedad reconoce y admira. Un rasgo más del héroe popular.

En las noticias que hacen referencia a la presencia de la mujer en la fiesta nacional editadas por NO-DO se descubren 4 tipos diferentes de contenidos, estilos y objetivos. Las primeras, y las que predominan, son las informaciones de tipo social, 
aquellas que reseñan actividades lúdicas, como capeas, en las que la protagonista es una mujer y la intención prioritaria de la noticia es su lucimiento personal, nunca dar cuenta del evento por sí mismo, por ejemplo, La Chunga torera. ${ }^{27}$ La cantante, vestida con un ajustado traje campero, torea con Luis Miguel Dominguín en una finca particular. Este tipo de reportajes son muy numerosos y tienen una vertiente muy publicitaria: permiten mostrar a la artista en un faceta desconocida para el gran público, actuando sobre la percepción y la comprensión que el espectador tiene sobre el personaje, obviamente para mejorarlo. Abbe Lane torea al alimón con Victoriano Cuevas $^{28}$ es uno de los muchos ejemplos que se pueden encontrar.

En esta línea hay que situar también algunos acontecimientos familiares. En La boda del torero Victoriano Valencia con Paloma Díaz, ${ }^{29}$ el baile nupcial fue sustituido por un toreo mano a mano entre los recién casados. Pero la mayor sorpresa llega al final: "Lola (Lola Flores) no quiso ser menos: torea al alimón y luego sola, por soleares". La noticia se cierra con unos planos medios de "la faraona" metida en faena. Las mujeres que aparecen toreando en las capeas suelen ser artistas, acostumbradas a las excentricidades y a las cámaras. Estos divertimentos taurinos se entienden como una diversión en las que las mujeres adquieren cierta relevancia por lo anecdótico de su conducta. En otras capeas sucede lo contrario: es el torero el que hace una exhibición de su arte, de sus pases y de su habilidad como lidiador para que las mujeres le admiren. Ellas aparecen envueltas en abrigos de pieles, elegantes, jóvenes, atractivas, alegres.

El segundo grupo de noticias está formado por las que plantean la presencia femenina en el ruedo como torera o rejoneadora. Aquí se construyen argumentos muy diferentes. Surge entonces el elemento cómico que constituye la esencia de otro bloque de noticias muy importante cuantitativamente en NO-DO, que se encuadra mayoritariamente en la sección Imágenes. Los títulos de las noticias indican claramente el tono en el que son abordadas: Señoritas toreras o Estella, mujer contra toro. El acento irónico del locutor recurre a los tópicos habituales para crear una presentación chistosa. Señoritas toreras ${ }^{30}$ trata de una corrida celebrada en México en la que participan varias mujeres. La información se completa con un reportaje previo en el que se explica la vida, la trayectoria y la preparación de las participantes:

Betty Ford (aparece jugando a tenis), además de bonita, es deportista y torera... Antes era estrella de cine, pero abandonó las pantallas para pasar a los ruedos. Su adiestramiento lo hace en la misma cancha en la que entrena con la raqueta.

Queda patente así la escasa profesionalidad de la torera, así como su condición de ex artista. Cuando Betty coge la muleta, la cámara se fija en su cuerpo, no en lo que hace: contrapicados y planos cercanos para resaltar sus atributos femeninos que constituyen el objeto principal de atención. La presentación de Juanita Aparicio, en el mismo reportaje, prolonga este tipo de exposición. En el caso de Juanita se resaltan sus cualidades como ama de casa. Aparece en el reportaje guisando, y "sus admiradores dicen que maneja el capote y la muleta como el dedal y la aguja". El locutor señala cómo la muchacha es protegida por su ayudante, quien le adiestra en los 
secretos de la estocada, y por su madre que se encarga de su aspecto físico. Los comentarios sobre la corrida son sarcásticos y muestran sin ambages la opinión de NO-DO: el lugar de la mujer está en el tendido y no en el ruedo. Aunque Betty Ford realiza una faena más o menos digna, el comentario del reportaje no deja pasar la oportunidad de recordar que se trata de una mujer:

(...) Cuidado, Betty, cuidado, que te puede hacer pupa (una pequeña cogida)... El bicho está un poco quedado, a lo mejor porque Betty es muy guapa. Clava una gran estocada. El público la aplaude y la piropea. Una oreja y, como no quieren que se vaya, da una vuelta al ruedo.

La locución más profesional se dedica a Juanita Aparicio: "a la verónica, con el capote a la espalda. Parón y desplante. Más derechazos que cualquier fenómeno de los buenos...". La conclusión final, la forma en la que se cierra el reportaje, vuelve a deslizarse por los tópicos: "y a esto le llaman el sexo débil".

El mundo taurino no respeta a la mujer por su falta de preparación y de seriedad. Esta cuestión es habitual en diversas noticias emitidas por NO-DO. Reportajes como Escuela taurina femenina en México ${ }^{31}$ presentan escenas que demuestran la incapacidad física de la mujer para desempeñar una labor digna en este terreno. Con mallas, jerséis, collares y pelo "de peluquería", las alumnas reciben sus clases prácticas. Cuando una mujer se siente amenazada por un becerro o bien sale corriendo o enseguida acude un caballero con la capa para protegerla. A las mujeres, según se deprende de estas noticias, les falta la valentía necesaria para enfrentarse al toro.

En los reportajes sobre las fiestas de Estella (Navarra) se repiten los mismos tópicos: el novio que se pone delante de la chica para protegerla y la falta de profesionalidad de las mujeres que torean con manteles - de cuadros, de flores, no importa-, paños de cocina e incluso trapos viejos destinados a la limpieza doméstica. Se comenta que entusiasmo no les falta, aunque la voz en off también aclara que las vaquillas fueron seleccionadas teniendo en cuenta a la afición femenina. Tampoco importa su arrojo: "El público protesta de que salgan con pantalones porque resta gracia al festejo". Pero el reportaje que resume perfectamente la esencia de esta categoría de noticias y el pensamiento a cerca de la relación mujeres y mundo de los toros es el titulado Las bellezas unidas, ${ }^{32}$ rodado en Palma de Mallorca. Ahí las "guapas oficiales" se atreven a torear:

(...) El becerro es listillo y sabe que no ha de quebrar estas hermosas figuras que lancean con garbo y valor... Sino te quitas tú, te quita el toro. Parece que se lo han aprendido. Ahora ponen banderillas como mojan pan en el chocolate (...).

Lo fundamental de una mujer es su aspecto externo: eso es lo que la debe ocupar. Salir al ruedo se entiende como una diversión, una broma, por eso la construcción audiovisual se hace a modo de gags. Aunque por lo general la aparición de las mujeres en los ruedos se observa con burla y condescendencia, el tercer grupo de noticias muestran la pericia y el buen hacer de algunas mujeres toreras.

Conviene recordar que la legislación prohibía, desde 1908, el toreo pie en tierra 
a las mujeres. Por tanto, las mujeres con deseos de dedicarse al toreo, no sólo tenían que demostrar su sobrada capacidad, sino también librar una tenaz lucha contra esta prohibición. Fue el caso de La Guerrita y La Garbancera. La polémica sobre el sexo de María Salomé, apodada La Reverte, desvela hasta dónde llega esta situación. Según algunos autores (Mérida, 1999: 101), era una mujer que tuvo que declarar que era hombre para seguir toreando. Según otros $-\mathrm{y}$ el propio NO-DO lo afirma en alguna ocasión ${ }^{33}$ - era, en realidad, un hombre.

Conchita Cintrón, actriz y ganadera, rejoneadora y torera de a pie, fue una de las mujeres más importantes que han pisado los ruedos. Chilena de nacimiento y afincada en Portugal desde 1950, se la conoció con el nombre de la Diosa Rubia o la Diosa de Oro. Recorrió triunfal los ruedos de todo el mundo toreando, interpretó la película Maravilla del toreo y fundó su propia ganadería (Sherwood, 2002: 177183). Fue, posiblemente, la mujer que más alabanzas recibió en la información cinematográfica: "el garbo y la donosura de Conchita Cintrón en Barcelona... su dominio y audacia... el manejo de la jaca con soltura sorprendente... despierta la admiración de la muchedumbre, en una plaza con un lleno rebosante (...)".xxxiv También Paquita Rocamora aparece en las pantallas como una auténtica profesional: “(...) la rejoneadora luce su habilidad (...)", aunque siempre los toreros se llevan los mejores elogios y el tono apasionado del locutor:

Lancea Montero y remata sus verónicas... Pedrés domina la faena con la derecha y sigue con poses en redondo... el público en pie, el Litri mirando al tendido, desplante de rodillas de espalda al novillo... vuelta al ruedo y ovación. ${ }^{35}$

Cabe añadir, en esta línea, a Lolita López Chávez, que solía participar junto a su hermano Cándido, y a Amina Asís Hernández, ambas rejoneadoras. Pero este tipo de noticias es escaso y, por tanto, resulta difícil valorar sus efectos en el espectador. Todo parece indicar que no se proporcionaron las referencias audiovisuales mínimas para crear una imagen profesional de la mujer en el mundo del toreo.

El cuarto bloque informativo, ofrece una mirada informativa particular en la que las referencias al sexo femenino solapan cualquier otro comentario sobre el valor, el esfuerzo o la diversión que produce la aparición de las mujeres en el ruedo: "En una temporada que se ha caracterizado por aparición de guerrilleros, complots, sabotajes, aquí está la otra cara mucho más bonita". Las rejoneadoras entran al ruedo: Adelina Texeira Muñoz, Lolita Muñoz, Antoñita Linares, Francisca Rocamora, la Princesita de Paris rivalizan en el dominio de sus jacas y en el arte de los rejones ${ }^{36}$. Los comentarios y los planos son profesionales, pero siempre termina añadiéndose una nota irónica: “(...) lances gentiles y pasos y pases de la mejor escuela. Un trago de agua fresca y al toro. Cada cuadrilla ni quita ni pone rey, pero ayuda a su señora. Se evidencia que la mujer necesita del apoyo del vilipendiado sexo fuerte (...)”. Pero ahí no queda todo, el final del reportaje remata la faena, en sentido literal:

(...) El público solicita las dos orejas o un beso. Con el beso se queda la jaca, con la desilusión de algún espectador que prefería que terminaran los toros como terminan las carreras ciclistas. 
Esta retórica se mantiene a lo largo de toda la existencia del noticiario. En 1974, NO-DO proyecta una noticia en color titulada Mujeres toreando en Salamanca. Carmencita Dorado y Rosarito de Colombia siguen siendo "señoritas toreras" que ocupan un lugar preferente en el cartel. Mientras se visten, antes de pisar la arena, la cámara se detiene en cómo se pintan los labios. Carmencita recibe un comentario sereno: "Puso voluntad y salero y la concesión de una oreja refrendó su quehacer". Pero Rosario, que toreó a pie, vestida con pantalón negro y torerilla roja, tenía el listón -masculino- muy alto. "Bueno, tal vez por aquello que la honradez es recompensada, se le concedió una oreja y el respetable aplaudió comprensivo."

En un número importante de informaciones NO-DO deja claro que la mujer, como protagonista de la fiesta, no forma parte de la liturgia taurina (Pizarroso, 2000), y que la lidia y el lenguaje taurino son masculinos (Abellá, 1996). El lugar de la mujer está en el entorno del torero (Grajal, 2002): la imagen de la mujer aparece unida a una forma de cultura por la vía sentimental. Puede decirse que los operadores de NO-Do se hicieron eco de la mentalidad popular igual que otros medios de comunicación social entonces. En agosto de 1975, al año de autorizarse la lidia de reses en plazas de toros a mujeres españolas, el diario Pueblo publicaba una entrevista con una nueva mujer torera. Las preguntas del periodista reproducen los estereotipos habituales en la locución difundida por NO-DO. Comienza el texto así: "Decididamente la mujer se "echa al ruedo. Al menos lo intenta (...)" y prosigue con: "¿cree que la mujer puede hacer algo serio en los toros? (...)". Sus afirmaciones son rotundas: "Pero esta es una profesión de hombres (...)."37

\section{Conclusión}

Un noticiario cinematográfico ofrece varias lecturas. Una es descubrir, a través de sus imágenes, cómo quiere la sociedad que produce ese noticiario ser vista, o cómo quiere que la vea el espectador. Esto nos lleva ineludiblemente a las personas que se encargan de traducir ese deseo colectivo, que distorsionan la realidad, pero también ayudan a definirla. Lo que las autoridades quieren mostrar -lo que los redactores suponen que pueden y deben mostrar- tiene un peso definitivo y, precisamente este factor, facilita encontrar la imagen que se quiere promover por parte de aquéllos que detentan el poder.

Así, la cobertura informativa que hace NO-DO de las actividades deportivas en las que aparece una mujer representa un reforzamiento de las imágenes estereotipadas y tradicionales de la feminidad y de la sexualidad femenina que quería proyectar el régimen franquista. Las mujeres poseen una presencia muy limitada en el mundo del deporte y circunscrita, únicamente, a aquellos ejercicios considerados adecuados para su organismo. La presencia femenina en las noticias deportivas de NO-DO depende del tipo de ejercicio que se realice. De esta manera, hay una serie de deportes como la natación, el baloncesto, esquí o algunas pruebas de atletismo en los que la presencia femenina es continua y activa, y las mujeres son sujetos deci- 
sivos que participan en todo tipo de juegos y competiciones. Mientras, en otros deportes considerados como "masculinos", como el fútbol o los toros, el papel de la mujer es marginal, porque no participa en el juego, sino que simplemente forma parte del espéctaculo que le rodea.

Sin embargo, otra posible lectura de un noticiario consiste en detectar el empuje de la realidad y cómo se refleja en las informaciones. Ha de tenerse en cuenta que cualquier intento de persuadir exige credibilidad: no todo lo que el noticiario quisiera proyectar podía ser proyectado (Paz, 2010). Es decir, NO-DO debía pagar también el peaje de la verosimilitud para ser realmente influyente: la sociedad también termina imponiendo de alguna forma ciertos temas y un mayor cuidado en la modulación del tono. Estas influencias se perciben en la forma de vestir, más laxa y permisiva según avanzan los años, y tambien, y de manera más importante, en la naturalidad y abundancia de noticias que relacionan a la mujer con el deporte.

Como queda demostrado, en los 60, las noticias relativas a la presencia de la mujer multiplican casi por dos a las que aparecieron en los años 50 y en tres a las que fueron proyectadas en los cines durante la década de los 40. Sin tener datos completos de los años 70, la proyección (36 informaciones en apenas 5 años) indica que la normalización del deporte dentro de la sociedad española también impulsa una imagen más moderna de la mujer. Sin embargo, un cosa es la presencia y otra muy diferente la construcción de sentido que se haga sobre esa presencia. Ahí no hay grandes variaciones en la evolución histórica.

Resulta muy interesante la comparación entre los deportes "femeninos", en los que las informaciones de NO-DO se muestran condescendientes e incluso animan la participación activa de las mujeres, y el deporte "masculino" por excelencia y los toros, en los que su presencia es exclusivamente pasiva. Curiosamente, en ambos espacios, la creación de sentido que se puede hacer sobre la representación femenina tiene características muy similares. Da igual que esté corriendo en una pista o viendo los toros de la plaza, la mujer nunca puede dejar de ser la mujer que quiere diseñar el sistema franquista.

Excluyendo las informaciones sobre atletismo en los 60, en los que el lenguaje y el enfoque es equiparable a los hombres, resulta muy habitual que la representación de la mujer en el deporte sea más para verla que para explicar su relación con ese deporte. Se puede hablar de un efecto escaparate: las mujeres se exponen para ser vistas, para exhibirse estéticamente, lo que hace que tenga una menor trascendencia la actividad deportiva o su destreza en ella. Esto se comprueba en el tratamiento informativo en el que importa mucho más observar a la mujer, bien en relación a la ropa que luce (esquí, patinaje) o como comic relief (alivio cómico) para dar una nota de humor (fútbol, deportes de invierno, etc), lo cual desnaturaliza una vez más la presencia del deporte, lo convierte en puramente accesorio y hace que las informaciones se centren en la mujer como objeto a observar, a entretener y a recrear. Paralelamente, la representación femenina en los toros repite e incluso refuerza aún más esta pauta. La continua presencia de la mujer al lado del torero, sin otra función en la corrida que estar, la sitúa nuevamente en el escaparate. ¿Es guapa? ¿Cómo viste? ¿Le quiere? Las preguntas que se derivan de la imagen no tienen nada que ver 
con los toros y sí exclusivamente con la valoración social que se pueda hacer de esa persona por su aspecto físico. Nada parecido sucede con el hombre. En el atletismo, la mujer tiene marcas bajas y compiten relativamente poco en comparación con los hombres, lo cual crea una sensación de que participan en un sucedáneo de competición. En los toros, sucede lo mismo con las capeas, una corrida menor, a la que se ve abocada la mujer por su inferioridad física y de valores (fortaleza, valor). Y ni siquiera en las capeas tiene un mínimo reconocimiento como "torera", es solamente un espacio más para momentos de humor.

El deporte femenino representado por NO-DO muestra dos tipos de mujeres muy diferentes y muy semejantes a la vez. Las distingue el grado de implicación en la actividad física, unas participan activamente mientras que otras se limitan a ser observadoras de lo que sucede en campos y ruedos. Pero las equipara una cuestión más profunda que nada tiene que ver con la actividad deportiva: su condición de mujer. El tratamiento que ambas reciben por el noticiario, que infravalora y aborda las noticias con cierta condescendencia, plasma, de forma evidente, las jerarquicas relaciones de género imperantes en la España franquista.

\section{Bibliografía}

ABELLÁ, C. (1996). Derecho al toro. El lenguaje taurino y su influencia en lo cotidiano. Madrid: Anaya \& Mario Muchnik.

AMADOR, P. (2003). "La mujer es el mensaje. Los coros y danzas de sección femenina en Hispano américa". En: Feminismo/s, no 2, Alicante: pp. 101-120.

DÍEZ, C. (1996). "Deporte y construción de las relaciones de género". En: Gazeta de antropología, $\mathrm{n}^{\circ}$ 12, Granada: 93-100.

FERRO, M. (1968). "Societé du Xxe. Siècle et histoire cinématographique". En: Annales économias, societés, civilitations, $\mathrm{n}^{\circ}$ 23: pp. 581-585.

Fundamentos del nuevo Estado (1943). Madrid: Vicesecretaría de educación popular

GONZALEZ AJA, T. (2005). "Monje y soldado. La imagen masculina durante el franquismo". En Revista Internacional de Ciencias del Deporte, $\mathrm{n}^{\circ}$ 1: pp. 64-83.

GORI, G. (2003). "Italy: Mussolini'sboys at Hitler's Olympics". En KRÜGER, A y MURRAY, W. (dir.) (2003). The Nazi Olympics: Sport, politics and appeasement in the 1930s. Urbana y Chicago: Universidad de Illinois Press, pp. 113-126.

(2004). Italian fascim and the female body: sport, submissive women and strong mothers. Londres: Routledge.

GRAJAL, M. A. (2002). Va por ellas. Mujeres de los toreros. Barcelona: Planeta.

GUTTMANN, A. (1991). Women's Sports: A history. Nueva York: Columbia University Press.

HURELAGA, J., (2009). "Historia contextualizada de la radio española del franquismo. 1940-1960". En: Historia y Comunicación social. N1 14, Madrid: pp. 367-386

LORING, T. (1983). "La sección femenina y la promoción de la mujer". En PRIMO DE RIVERA, P. (1983). Recuerdos de José Antonio. Madrid: Dyrsa.

MATUD, A. (2008). "La incorporación del cine documental al proyecto de NO-DO". En Historia y Comunicación social, $\mathrm{n}^{\circ}$ 13, Madrid: 105-118 
MÉRIDA, M. (1999). La torería. Madrid: Espasa Calpe.

MORGAN, S. (2006). "Mussolini's boys (and girls) Gender and sport in fascist Italy". En: History Australia, no 1, vol. 3: pp. 04.1-04.12

PANADÉS Y POBLET, J. (1878). La educación de la mujer. Tomo II. Barcelona: Jaime Seix y Compañía.

PAZ, M.A. (2010). "Educación universitaria y franquismo: la visión de NO-DO”, en Image et Education, $7^{\circ}$ Congrés International, Le Grimh, Lyon.

(2007) "Mujer y Formación Profesional durante el franquismo: NO-DO 1943-1975", en Revue Pandora (Féminités), l'Université de Paris VIII, coordinado por Michèle Ramond y Danièle Bussy-Genevois, pp. 133-145.

PIZARROSO QUINTERO, A. (2000). La Liturgia taurina: protocolo, ritual, etiqueta y ceremonia en el mundo de los toros. Madrid: Espasa Calpe.

PRIMO DE RIVERA, P. (1961). La enseñanza doméstica como contribución al bienestar de la familia española. Madrid: Colección Congreso.

RABAZAS, T. (2000). "La educación física del magisterio femenino en el franquismo". En: Revista complutense de educación, $\mathrm{n}^{\circ}$ 2, Vol. 11, Madrid: pp. 176-198

RICHMOND, K. (2004). Las mujeres en el fascismo español. La sección femenina de la falange, 1934-1959. Madrid: Alianza ensayo.

ROSADO, M. (2003). "Mujeres en los primeros años del franquismo. Educación, trabajo, salarios (1939-1959)". En CUESTA BUSTILLO, J. (dir.) (2003). Historia de las mujeres en España. Siglo XX. Tomo II. Madrid: Instituto de la Mujer, pp. 14-81.

Sección Femenina (1941). Anuario de Sección Femenina. Madrid: Delegación nacional de la Sección Femenina.

SHERWOOD, A. L. (2002). Yankees in the afternoon: an ilustrated history of American bullfighters. Jefferson: Mc Farland \& Company.

SUÁREZ, L. (1993). Crónica de la sección femenina y su tiempo. Madrid: Asociación Nueva Andadura.

VON DER LIPPE, G. (2000). "Medical text of gender, sexuaity and sport in Norway". En Journal of Sport History, Vol. 27, $\mathrm{n}^{\mathrm{o}} 3$ : pp. 481-495.

ZAGALAZ, M.L. (1998). La educación física femenina en España. Jaén: Universidad de Jaén.

\section{Notas}

1 Esta investigación ha sido realizada en el marco del programa de Creación y consolidación de grupos de investigación BSCH-Universidad Complutense de Madrid, convocatoria 2011, grupo de investigación: Historia y estructura de la comunicación y del entretenimiento. También forma parte del proyecto de investigación Historia del entretenimiento en España durante el franquismo: cultura, consumo y contenidos audiovisuales (cine, radio y televisión) (HAR2008-06076/ARTE), financiado por el Ministerio de Ciencia e Innovación.

2 (1958), Teresa, año $\mathrm{V}, \mathrm{n}^{\circ} 53$.

3 GARCIA FERRANDO, M. (1997). "La mujer en el deporte de la alta competición: conflicto de roles ya adaptación al modelo deportivo dominante. El caso del atletismo 
españo". En V.V.A.A. Mujer y deporte, Madrid: Instituto de la mujer: pp.21-51. GARCIA DIEZ, A. (2006). "La evolución histócia y social de la mujeren la práctica física y el deporte". En Lecturas: Educación física y deportes, $\mathrm{n}^{\circ}$ 99. revista digital: $h t t p: / / w w w . e f d e-$ portes.com/efd99/mujer.htm, BARATA, N., SOLER, S. (2004)."Mujer y deporte en España: estado de la cuestión y porpuesta interpretativa. En APUNTS, Educación física y deporte, $\mathrm{n}^{\mathrm{o}}$ 76: pp. 71-76 o DÍEZ, C. (1996). "Deporte y construción de las relaciones de género". En: Gazeta de antropología, n 12, Granada: 93-100.

4 MANRIQUE ARRIBAS, J.C. (2003). "La educación física femenina y el ideal de mujer en la etapa franquista". En Revista internacional de medicina y ciencias de la actividad física y el deporte. $N^{\circ}$ 10: 83-100. ZAGALAZ, M.L. (1998). La educación física femenina en España. Jaén: Universidad de Jaén. RABAZAS, T. (2000). "La educación física del magisterio femenino en el franquismo". En: Revista complutense de educación, $\mathrm{n}^{\mathrm{0}} 2$, Vol. 11, Madrid: pp. 176-198 o MANRIQUE, J.C., TORREGO, L. LÓPEZ, V. y MONJAS, R. (2009)."Factopres que determinaron una educación física y deportiva de género durante el franquismo". En APUNTS, Educación física y deporte, 98: 5-14

5 La metodología se basa en la propuesta de María Antonia Paz en "Mujer y Formación Profesional durante el franquismo: NO-DO 1943-1975", en Revue Pandora (Féminités), l'Université de Paris VIII, coordinado por Michèle Ramond y Danièle Bussy-Genevois, mayo 2007, pp. 133-145.

6 "La política del estado falangista, orientado hacia la unidad y fortalecimiento de cuantas actividades conduzcan a la más firma potencia de la Patria, no puede descuidar en modo alguno al deporte, en el que encuentra uno de los principales instrumentos para la entera educación del hombre español". Decreto que establece la Delegación Nacional de Deportes de FET y de las JONS. (22-02-1941) Fundamentos del nuevo Estado (1943). Madrid: Vicesecretaría de educación popular

7 Sección Femenina (1941). Anuario de Sección Femenina. Madrid: Delegación nacional de la Sección Femenina

8 (1969). Teresa, nº 181, año XVI.

9 “¿Qué hemos de hacer para lograr un cuerpo sano, robusto, desarrollado, apto para le trabajo y la belleza? Nutrirlo de un aire sano, de una limentación sobria, sustanciosa y saludable desde el seno materno hasta el desarrollo completo de la vida; que tenga siempre un medio, una habitación aireada, ventilada, asoleada, que goce siempre de una respiración pura, qué esté libre de la sencillez y sanidad de los principios higiénicos, que estos seba perennemente los conservadores de su vigor, de su salud, de su existencia eterna". En este tratado sobre educación femenina del siglo XIX no se indica, en ningún momento, la necesidad del ejercicio físico para conseguir una buena forma física. PANADÉS Y POBLET, J. (1878). La educación de la mujer. Tomo II. Barcelona: Jaime Seix y Compañía, p. 221.

10 Medina, 10-07-1941.

11 Este tipo de deportes son los recomendados para las mujeres según varios higienistas europeos. GORI, G. (2004). Italian fascim and the female body: sport, submissive women and strong mothers. Londres: Routledge, p. 76. VON DER LIPPE, G. (2000). "Medical 
text of gender, sexuaity and sport in Norway". En Journal of Sport History, Vol. 27, n 3: pp. 481-495.

12 La cuantificación se ha realizado a partir de un informe elaborado por los empleados del Archivo NO-DO titulado La mujer española en la Historia del deporte (1943-1977).

13 Travesía al Puerto de Barcelona. Noticiario 822 A (1958).

14 Travesía a nado del Lago de Bañolas. Noticiario 612 B (1954).

15 En la década de los cincuenta había 29.127 afiliadas según datos de PRIMO DE RIVERA, P. (1961). La enseñanza doméstica como contribución al bienestar de la familia española. Madrid: Colección Congreso, p. 27. Este número representaba un 2,4 \% de la población femenina soltera trabajadora. En RICHMOND, K. (2004). Las mujeres en el fascismo español. La sección femenina de la falange, 1934-1959. Madrid: Alianza ensayo, p. 187. Según los datos del anuario estadístico de España de 1958, en el curso 1949-1950 se matricularon unas 8.000 mujeres en las universidades españolas, aproximadamente unas 2.500 menos que en el curso 1955-1956. ROSADO, M. (2003). "Mujeres en los primeros años del franquismo. Educación, trabajo, salarios (1939-1959)". En CUESTA BUSTILlO, J. (dir.) (2003). Historia de las mujeres en España. Siglo XX. Tomo II. Madrid: Instituto de la Mujer, p. 43.

16 Gimnasia y Folclore en el Palacio de Deportes. Noticiario 1002 C (1962).

17 Cursos de esquí de la Sección Femenina. Noticiario 8 (1943).

18 Sobre las heladas pistas. Noticiario 470 A (1952).

19 La moda en la nieve. Invención de la elegancia femenina. Imágenes 211 (1949).

20 "La Sección Femenina ha sido la que ha logrado el milagro este milagro de que tres equipos de baloncesto formados por mujeres tomen parte en un campeomato nacional." Medina, 19-07-1942.

21 Olimpiada Universitaria en Barcelona. Noticiario 535 B (1953).

22 V Trofeo Canguro Atletas japoneses y españoles. Noticiario 1067 A (1963).

23 Patinaje en el Palacio de Deportes de Madrid. Noticiario 1187 A (1965).

24 (1958). Teresa, $n^{\circ}$ 50, año V.

25 Cada domingo. Imágenes 1110 (1964).

26 "Ya los saben: si el hombre de su vida es aficionado al fútbol -¿hay alguno que no lo sea?instruyase en la materia. Solo así es posible que lleguen a consideranos algún día como seres dignos de ser tenidos en cuanta para las cosas serias de verdad". (1968). Teresa, $\mathrm{n}^{\circ}$ 174, año XV.

27 La Chunga torera. Noticiario 851 B (1959).

28 Abbey Lane es la mujer de Xavier Cugat. Noticiario 922 B (1960).

29 La boda del torero Victoriano Valencia con Paloma Díaz. Noticiario 1503 A (1971).

30 Señoritas Toreras. Imágenes 600 (1956). 
31 Escuela taurina femenina en México. Noticiario 1245 A (1966).

32 Las bellezas unidas. Imágenes 946 (1963)

33 Mujeres toreando en Salamanca. Noticiario 1658 (1974).

34 Arte taurino. Noticiario 134 A (1945).

35 Albacete. Paquita Rocamora. Los diestros Montero, Pedres y Litri. Noticiario 700 B (1956).

36 Corrida de toros por amazonas en Antequera, Málaga. Noticiario 1400 B (1969).

37 Pueblo, 7-08-1975.

\section{Los autores}

Fátima Gil es profesora ayudante doctora de la Universidad Internacional de La Rioja. Imparte las asignaturas de Teoría e Historia de la Imagen, Historia de España e Historia del cine. Es autora del libro Españolas en un país de ficción: mujer y cine durante el franquismo (1939-1963) (Rialp, 2011) así como del manual Teoría e Historia de la Imagen (Síntesis, 2011).

José Cabeza es profesor Titular interino en la Facultad de Ciencias de la Comunicación, de la Universidad Rey Juan Carlos. Imparte las asignaturas de Crítica de cine, Televisión y vídeo, Información audiovisual y Guión audiovisual. Es autor de: El descanso del guerrero. El cine en Madrid durante la Guerra Civil española 1936-39 (Rialp, Madrid, 2005) y La narrativa invencible. Cine de Hollywood en Madrid durante la Guerra Civil española (Cátedra, Madrid, 2009). 